\title{
Laboratory experiment with reduced scale model of a petroleum production riser and the understanding of involved phenomena
}

\author{
Eduardo H. dos Santos (EM), Mateus G. Ribeiro (EM), Vinicius H. S. Ribas (EM) \\ Prof. Dr. Celso K. Morooka (orientador), Humberto Arakaki Jr. (monitor), Caio C. O. Trigo (técnico)
}

\section{Resumo}

This work presents laboratory experiment with reduced scale of an idealized model of a vertical riser during installation process. Experiments were performed simulating platform motions under wave action. The main interest is to analyze vibrations of a riser at several frequencies. The model is a tube attached at one end to a motor and hanging at the other. Results show that largest displacements occur when the tube is placed in air and excited with frequencies close to its natural frequencies.

Keywords: Petroleum Engineer, Riser, Maritime Systems.

\section{Introdução}

Risers são tubos feitos de aço usados para ligar os poços no fundo do mar às plataformas na superfície, com finalidade de produzir petróleo. Ou também, podem servir na captação de água fria do mar para resfriamento de equipamentos e partes do processo nas plataformas de produção.

O objetivo desta pesquisa é acompanhar a montagem e realização de um experimento de um modelo em escala reduzida de um riser (Figura 1) e verificar a reação que terá variando-se a freqüência de oscilação na vertical e também na horizontal, em um tanque com água e sem água, respectivamente.

\section{Resultados e Discussão}

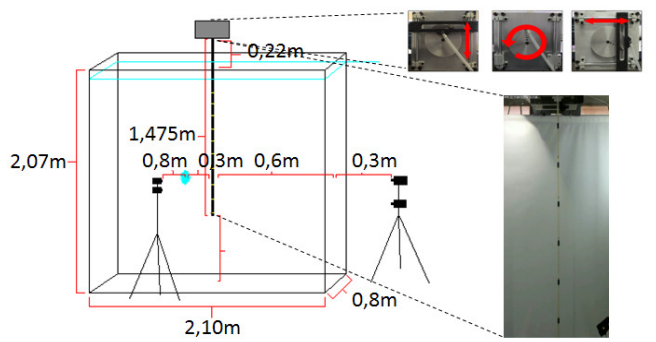

Figura 1. Modelo utilizado nos experimentos.

O tubo de silicone (riser) foi dividido em dez segmentos e para cada um deles obteve-se 0 deslocamento em função do tempo para as freqüências de $0,20 \mathrm{~Hz}$ a 2,00 Hz, além das freqüências naturais (Tabela 1).

Tabela 1. Freqüências naturais do tubo.

\begin{tabular}{|c|c|c|c|c|c|}
\hline & \multicolumn{5}{|c|}{ Freqüências naturais (Hz) } \\
\hline Ar & \multicolumn{2}{|c|}{0,48} & 1,44 & \multicolumn{1}{|c|}{1,88} \\
\hline Água & 0,12 & 0,28 & 0,50 & 0,79 & 1,13 \\
\hline
\end{tabular}

Nos experimentos realizados com água, os deslocamentos foram menores em comparação com o ar, e que as maiores amplitudes ocorreram nas freqüências naturais $0,48 \mathrm{~Hz}$ e $1,44 \mathrm{~Hz}$ para o tanque sem água e $0,40 \mathrm{~Hz}$ e $1,80 \mathrm{~Hz}$ para 0 tanque com água, conforme observado nas Figuras 2 e 3, que mostram as amplitudes de deslocamento nos experimentos realizados.
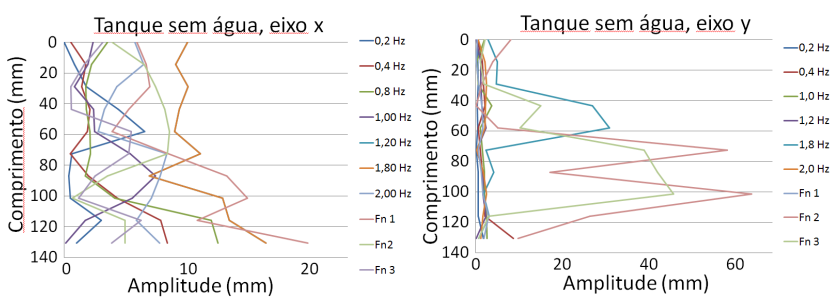

Figura 2. Amplitudes no tanque sem água.
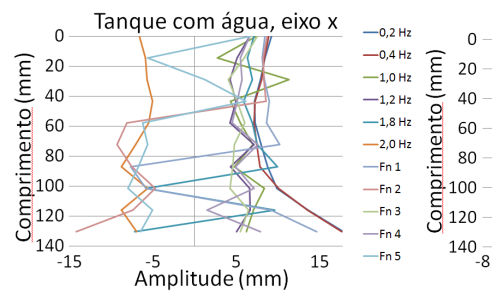

Tanque com água, eixo y

Figura 3. Amplitudes no tanque com água.

\section{Conclusões}

O tubo sofre maiores deslocamentos quando é movimentado em freqüências próximas às freqüências naturais (ressonância).

O efeito do amortecimento da água é maior em relação ao ar, diminuindo as amplitudes de deslocamento, o que aumenta a vida útil do riser.

\section{Agradecimentos}

Os autores agradecem à CNPq e a Pró-Reitoria de Pesquisa da Unicamp. 